\title{
LA SUERTE: TRÁNSITOS ENTRE EL ARTE Y ACTIVISMO
}

\section{La Suerte: transits between art and activism}

\section{María Fernanda Cartagena}

\author{
ISSN (imp): 1390-4825 \\ ISSN (e): 2477-9199
}

Fecha de recepción: 10/01/18

Fecha de aceptación: 11/29/18

\section{Resumen:}

La práctica estético-política de La Suerte (Sofía Acosta Varea, Quito, 1988) es un importante referente dentro del medio artístico y de los movimientos ciudadanos emergentes, que han alcanzado gran protagonismo durante la última década al concebir nuevos modos de organización, colaboración e intervención crítica y creativa en aras de la transformación social. A través de diversos lenguajes, morfologías, medios y tácticas artísticas, La Suerte ha contribuido a plasmar renovados y conmovedores imaginarios que acompañan las luchas por los derechos de las mujeres y de la naturaleza. A continuación un repaso por su algunas de sus propuestas más significativas que marcan su experiencia vital como artista mujer y activista. Esta doble inscripción le ha conducido a importantes reflexiones, giros y posiciones que informan los múltiples modos en los que transita y logra incidir en el campo del arte y los movimientos sociales.

\section{Palabras clave:}

activismo, arte callejero, arte urbano, grafiti, feminismo, transformación social, posextractivismo, ecofeminismo.

\section{Abstract:}

The aesthetic-political practice of La Suerte (Sofía Acosta Varea, Quito, 1988) is an important reference within the artistic milieu and the emerging citizen movements that have achieved great prominence during the last decade, by conceiving new modes of organization, collaboration and critical and creative intervention pursuing social transformation. Through diverse artistic languages, morphologies, media, and tactics, La Suerte has contributed to shaping renewed and moving imaginaries that accompany the struggles for women's and nature's rights. The following is a review of some of her most significant proposals, marked by her vital experience as a woman artist and activist. This double inscription has led her to important reflections, turns and positions that inform multiple ways in which she walks between and manages to impact the field of art and social movements.

\section{Key Words:}

activism, street art, urban art, graffiti, feminism, social transformation, post-extractivism, ecofeminism.

\section{Biografía de la autora:}

María Fernanda Cartagena (1970, Quito). Investigadora, curadora y gestora. B.A en Historia del Arte por The American University D.C., obtuvo una Maestría en Film \& Visual Cultures por Middlesex University en Londres. Sus temas de investigación son los vínculos entre el arte y la política en el arte moderno y contemporáneo, la teoría decolonial aplicada al arte, y las prácticas espirituales en vínculo con las prácticas artísticas. Ha desarrollado varios proyectos edu-cativos y curadurías para el campo de los museos en Ecuador. Ha sido docente de la PUCE, UASB, FLACSO y UCE. Actualmente se desempeña como directora del Museo de Arte Precolombino Casa del Alabado. 
La movida de arte callejero en la última década ha tomado el pulso a Quito quizá como ninguna otra expresión cultural. Entre el anonimato, las subculturas, el estilo de autor, los festivales municipales, la institución arte y las marcas comerciales, los artistas urbanos han irrumpido en diferentes circuitos y escenarios generando acalorados debates y dilemas sobre la función y circulación de su arte. Lo que hoy no está en duda es que las múltiples y contradictorias caras de la ciudad están mediadas por enigmáticos y delirantes personajes que trazan cartografías críticas y nuevas mitologías urbanas.

El arte de La Suerte (Sofía Acosta Varea, Quito, 1988) emerge desde la trinchera del arte callejero, un medio predominantemente masculino, donde rápidamente logra despuntar. A los 19 años, integra el colectivo Los Fenómenos, conformado por 10 hombres y 2 mujeres, quienes lideran el proyecto ocupa Madriguera Tóxica en una casa por atrás del edificio Benalcázar 1000. Las paredes del lugar apenas lograban contener la creatividad desbordada de jóvenes artistas y músicos que intervenían el espacio fusionando estéticas mientras respondían a un genuino impulso de libertad creativa. Así, su iniciación en las artes está marcada por la irreverencia, autogestión, fugacidad, colaboraciones y el "hazlo tú mismo" incitado en talleres de fanzines, stencils o murales. En este vibrante período, La Suerte aprende a trabajar con rapidez, a gran escala, y recibe su nombre artístico por misteriosas frases para la buena fortuna que dejaba en fachadas. En medio de la crudeza de la urbe y compartiendo muros e intersticios con las imágenes estridentes, descarnadas o edulcoradas de otros artistas callejeros, sus pintadas de mujeres escuálidas de ojos grandes, senos flácidos y vientres abultados sobresalían por su conmovedora vulnerabilidad. De este período, también son sus obras, intervenciones y hasta vestuarios realizados con basura reciclada como rechazo al consumismo y despilfarro.

\section{Viaje interno}

Del universo de ilustraciones independientes artesanales y digitales, fue la novela gráfica Virus Tropical de PowerPaola con la que La Suerte se conectó de inmediato. Le resonó la frescura con que esta artista ilustraba su biografía develando estructuras y jerarquías sociales a partir de escenas tragicómicas en el tránsito de niña a adolescente en el seno de una familia de clase media liderada por mujeres. Como gran parte de las más interesantes artistas, La Suerte colocará su vida como eje de exploración micropolítica. El planteamiento básico y radical de "lo personal es político" en su obra se traduce en posturas compartidas por otras artistas y teóricas feministas como la conciencia y autoconciencia de su experiencia como mujer, la valentía de poner abiertamente en juego su subjetividad, o el abordaje de aspectos biográficos y autobiográficos para deconstruir procesos de identidad e identificación (Cordero Reiman y Sáenz, 2007, pp. 6-8) Así, la artista pasará de las fachadas y grandes muros a las habitaciones y cajones en la casa de sus abuelos en Sangolquí. Dirigirá su mirada a los manteles, álbumes de fotos y menajes percibidos como silenciosos contenedores de secretos, obsesiones y convenciones. En la muestra "Más es más" (CAC, 2013) presentó elegantes platos de una vajilla intervenidos con dibujos de mujeres diversas y contenidos relativos a lo que su abuela mantenía: "No se puede hablar en una mesa".

Con el nacimiento de su hijo Sol, emprenderá un sensible ejercicio de introspección. Se inspira en la creencia popular de autocuidado tras el parto cuando, en sus palabras, “(...) muchas abuelas, parteras y mujeres sabias creen que cuando un guagua nace, la madre debe permanecer junto a él con las cortinas cerradas, tomando caldo de pollo por 40 días" (S. Acosta, comunicación personal, 4 de abril de 2018). Desde este retiro, con tintas, lápices de colores y hojas de cuaderno, realizará un dibujo diario por 40 días desde el día en que nació Sol. Su serie La Cuarentena es un diario íntimo y una contranarrativa a la imagen idealizada de la maternidad que tanto la historia del arte como la publicidad propagan. Los textos y dibujos, con sutil humor, ternura y sobre todo transparencia, plasman ese lado oscuro y humano del posparto que se intenta negar, donde la herida, el cansancio o la incertidumbre se toman el cuerpo, mente y espíritu.

\section{Activismo amoroso}

Activistas vieron en La Cuarentena (muestra colectiva La Limpia, Galería Pensasiete, 2013) una estética y subjetividad afín a las nuevas luchas por los derechos de las mujeres. A partir de esta obra, La Suerte emprende una serie de colaboraciones con colectivos feministas para ilustrar publicaciones independientes por la defensa de la vida y salud de las mujeres como Aborto con medicamentos, información segura para decidir (Colectiva Salud Mujeres, 2014) y Retratos del encierro. Sobrevivientes a las clinicas de deshomosexualización (Corporación Promoción de la Mujer/Taller de Comunicación Mujer, 2017).

Hoy más que nunca, los activismos incorporan las artes visuales y las artes vivas para comunicar y convocar de manera creativa, alternativa e inmediata a públicos diversos. Diana Coryat (2018), comunicadora y educadora popular, en su investigación sobre el movimiento social 
Yasunidos, analiza la importancia que asumen las prácticas simbólicas al interrumpir el poder mediático y desplazar la centralidad del desarrollo capitalista con imágenes creadas desde abajo y compartidas de manera horizontal. La Suerte participa activamente en ese tejido de prácticas y batalla simbólica creando imaginarios de contrainformación frente al poder con importantes plataformas y colectivos que denuncian la violencia contra la mujer, el extractivismo y el ecocidio como son VIVASNOSQUEREMOS, en contra del feminicidio en Ecuador; Minka urbana alternativas vivas, que articula las luchas antimineras del campo con la ciudad; Tandana, proyecto de gastronomía vegana y activista por los derechos de los seres vivos, y NOESTAMOSTODAS, plataforma mexicana que busca visibilizar los feminicidios. Su postura en medio de estas iniciativas no es esporádica o novelera, sino vital. Ha cultivado el respeto por la naturaleza y la justicia social desde muy niña acompañando a su padre y madre en marchas indígenas por la defensa del agua y la tierra.

El vínculo entre arte y política es un tema complejo, y más todavía la relación entre arte y activismo. La Suerte se autodefine como aliada de colectivos sociales a quienes admira por llevar adelante procesos difíciles, largos y asamblearios. De todas maneras, la vertiginosa dinámica de las luchas sociales demanda inmediatez de respuesta y los artistas deben estar preparados para colaborar o intervenir. La ilustración le ha brindado un lenguaje práctico con el que aporta a la coyuntura sociopolítica de manera directa, clara y oportuna. De su vinculación con los movimientos y colectivos, la artista destaca los aprendizajes sobre realidades aparentemente lejanas, pero que, alarmantemente, están más cerca de lo que nos imaginamos, como por ejemplo la incidencia y complicidad de la religión, familia y policía en la violación de los derechos de las diversidades sexo-genéricas.

Sobre los diferentes modos de ejercer el activismo, define su camino como un activismo no violento o "feminismo amoroso" distanciándose de acciones agresivas que, desde su parecer, reproducen el sistema machista y misógino (S. Acosta, 2018). Repara en cierto feminismo que se manifiesta de modo visceral y está convencida de que la transformación es posible desde el juego (estético), desde la polisemia de los gestos mínimos y desde un costado más amigable, opciones afines al principio zapatista de proponer y no imponer con el que se siente identificada.

En otro orden, está consciente del lugar privilegiado y no exento de complejidades que los artistas ocupan para representar y construir imaginarios de grupos afectados por inequidades o injusticias. Por experiencia, sabe que, más allá de las buenas intenciones, se puede caer fácilmente en la romantización y folclorización, generando imágenes muy distantes a cómo los grupos se ven o identifican. Consciente de que la representación artística, sus estilos y lenguajes no son neutrales, advierte el peligro de lo que denomina "una onda medio indigenista sin ningún criterio, porque está de moda". Este tipo de reflexiones la han conducido a seleccionar y a "autocensurarse" en ciertos temas. Reconoce se siente más cómoda explorando su vida y vinculando las luchas del campo desde la mirada de la ciudad. Si en algún momento se vio respondiendo a temas antimineros y petroleros desde un tono "políticamente correcto", supo dar un giro hacia una mirada más personal, sutil y femenina ( $S$. Acosta, 2018).

\section{Estética ecofeminista}

La intersección arte, ecología y feminismo se da de manera fluida y holística en su exhibición individual Esencial (Galería El Conteiner, Pobre Diablo, 2016). Esta propuesta se desarrolla en dos momentos. Primero una investigación artística que incorpora al viaje por diferentes regiones del país con el propósito de relacionarse profundamente con prácticas tradicionales y ancestrales comprometidas con la valoración de las semillas campesinas, nativas y orgánicas. La segunda fase se concreta en una exhibición donde comparte su experiencia a través de dibujos, un video y una instalación-ambiente. Estas obras remiten a un proceso abierto y en marcha donde se explora el potencial ecológico, filosófico, espiritual, estético y vital de la semilla y su vínculo con el costado creador, protector y transformador de la mujer. El video presentaba derivas íntimas, azarosas y poéticas capturadas por la artista o por su hijo con la cámara del celular. El montaje de estas imágenes fue experimental y expresaba una subjetividad política a través de contraponer escenas, aparentemente inconexas de su hijo, paisajes, encuentros con guardianes de semillas, sonidos y conversaciones. Por otro lado, el espectador era invitado a ingresar descalzo, en silencio y despacio a un recorrido enigmático, oscuro y húmedo que, como acción ritual, conducía a un núcleo central u ofrenda a la naturaleza. La serie de dibujosilustraciones realizada en pigmentos de achiote, sangre de drago, col morada o remolacha homenajeaban a las guardianas de las semillas y a la biodiversidad evocada con gran delicadeza y naturalidad en infinidad de hojas, flores, frutos y raíces.

El análisis que la teóloga feminista Ivone Gebara (2000) ha realizado sobre las alianzas entre ecología y feminismo, aportan a la comprensión de la relación que 
La Suerte establece entre mujer y naturaleza en esta serie. La artista responde a una postura política crítica y no una visión idealizada encaminada a trazar una esencia inmutable y compartida entre estas dos dimensiones. En su viaje experimentará de primera mano cómo las mujeres son las primeras afectadas por las malas políticas relativas al medio ambiente o al desarrollo, y de ahí su rol protector. Esta observación empírica y lectura crítica es la que Gebara resalta del ecofeminismo, ya que sitúa la problemática en las relaciones de poder sobre las mujeres y en cómo estas fuerzas determinan que en sus manos quede el asegurar la vida, cuidar la alimentación y garantizar la salubridad (pp. 19-24).

Esta serie contribuye de manera particular al conceptualismo del sur global, por la crítica que subyace a los ideales de modernidad, desarrollo y capitalismo, por la elección de pigmentos naturales como medio y contenido, y por la desmaterialización que acontecerá dada la evanescencia de los tintes. La Suerte denomina a esta apuesta estético-política como "arte posextractivista", a través de la cual desafía los modos tradicionales de producir arte y de crear imaginarios.

La vertiente conceptual del arte le ha permitido experimentar con mayor detenimiento connotaciones discursivas de los lenguajes visuales, sonoros y corporales. Para la acción "Sembrando Rudas" (Festival de arte público GRAFFF, 2012) eligió el gesto mínimo de plantar rudas en parterres, parques y casas en barrios de Ambato como práctica de sanación personal y pública. También entregó fanzines con los usos populares de este poderoso arbusto conocido por aliviar ciclos menstruales, interrumpir la gestación y limpiar las malas energías. Otra acción en la esfera pública fue " $C A C A N A N$ " ("un camino de mierda") que formó parte del proyecto "Derivas", organizado por el Museo Nómada, y presentado en Más Arte Galería (2016). Este proyecto fue una iniciativa independiente y crítica, planteada desde los márgenes de la Conferencia de las Naciones Unidas sobre Vivienda y Desarrollo Urbano Sostenible, Hábitat III. La propuesta de La Suerte, documentada en fotografías, consistió en tomar una muestra de agua del río Machángara, afluente contaminado que cruza gran parte de la ciudad. Mezcló este líquido con pintura amarilla y con esta sustancia tóxica fue marcando una línea en el piso mientras caminaba a la Galería, señalando los múltiples niveles de descomposición de la ecología social. La artista se propuso "evidenciar tanta mierda que hay en la ciudad, tanto real como simbólica". Nuevamente colocó la naturaleza en el centro de su propuesta, esta vez para cuestionar condiciones sociales, medioambientales y políticas. Dentro de la sabiduría femenina y de la biología medioambiental, cuando una corriente está envenenada, todo empieza a morir.

Otras obras en clave conceptual las ha llevado a cabo dentro del proyecto Análoga, gestionado por un grupo de artistas interesados en los principios, lenguajes y tecnologías de la fotografía tradicional. Para la exhibición “Análoga 2" (Galería El Conteiner, Pobre Diablo, 2014), conjuntamente con Juan el Raro, diseñan un dispositivo participativo elaborado a partir de materiales descartables, un arduino y una cámara Polaroid con el cual capturar el alma de los fotografiados por solo USD 2, Actualmente, la artista integra el colectivo Mirador con Adrián Balseca y Boloh Miranda, interesado en develar la criminalización de activistas y líderes sociales que se llevó a cabo durante el correismo por su resistencia y lucha contra el extractivismo. El colectivo produce audiovisuales a partir de un tipo de investigación militante con imágenes y archivos de medios de comunicación, judiciales, entre otros.

\section{Soltar}

Lejos de sentirse cómoda con un estilo de autor reconocible, la idea de caer en una gráfica marcada y la propensión a que la fijen en determinado estilo han sido alertas que la motivan a permanecer en búsqueda continua y a poner en crisis zonas de confort. Por esto, si bien reconoce que las colaboraciones no son fáciles, ha tomado parte en procesos que favorecen la improvisación, el azar y la deconstrucción de lenguajes ( $\mathrm{S}$. Acosta, 2018). Esto tiene que ver con lograr soltar esos espacios de control y seguridad en el arte para fluir con lo impredecible en cada encuentro con el otro. En esta línea se embarcó en un ejercicio creativo con el artista Pancho Baquerizo, denominado "Laberintos del pensamiento" (Centro Cultural Carlos Fuentes del Fondo de Cultura Económica, Quito, 2017) bajo la consigna de que cada uno dibujaría la vida del otro a partir de la escucha de sus relatos y testimonios. ¿Qué cuentas de tu vida?, ¿cómo el otro te imagina?, ¿qué decide representar y omitir? fueron algunas preguntas que esta experiencia removió alrededor de la performatividad de identidades y sus mediaciones a partir de la (auto) representación.

Igual de desafiante y enriquecedora fue la colaboración con David Sur para ilustrar el disco $\mathrm{Me}$ fui a volver de la banda quiteńa Guardarraya. En este caso, la pauta que establecieron los artistas fue permitirse intervenir en sus dibujos. Desde el juego mutuo de borrones, añadidos o yuxtaposiciones, surgió lo que se podría denominar como formas "abigarradas" a partir de la noción de chixi de la activista aymara Silvia Rivera Cusicanqui (2010). Esto es la idea "de algo que es y no es a la vez" y que, por lo tanto, contiene la potencia de lo 
indiferenciado. No se refiere a una mezcla armónica de estilos, formas y subjetividades, sino de la coexistencia de diferencias que se complementan.

No es común que artistas logren inscribir de manera precisa y relevante su práctica tanto en la esfera del arte como del activismo. La Suerte no idealiza estas esferas y mantiene una mirada atenta a sus lógicas, por lo que transita entre estos campos reconociendo sus complejidades y potencialidades sin perder una actitud fresca, frontal y alegre. Su práctica es dinámica e imprevisible en cuanto a lenguajes, morfologías, medios y tácticas, y sabe nutrirse de lo mejor de las diferentes esferas como, por ejemplo, la autogestión del arte urbano, la investigación conceptual del arte contemporáneo o la lectura crítica de la realidad de los movimientos sociales.

Su práctica artística se inscribe dentro de las voces que han irrumpido con fuerza para denunciar violencias o demandar derechos frente a la censura a la libertad de expresión, la criminalización de la protesta ciudadana, la persecución de líderes sociales, y demás formas de opresión y violencia hacia individuos, mujeres, colectivos y movimientos sociales ejercidas durante la década del correato. La poética-política de La Suerte ha logrado catalizar imaginarios, deseos y luchas de una amplia y emergente subjetividad comprometida con la transformación social desde un activismo amoroso que inspira y vincula.

\section{Referencias}

Acosta, S. (2018). Entrevista por María Fernanda Cartagena, 4 de abril.

Coryat, D. (2018). Yasunidos: nuevas subjetividades, comunicación y pos-desarrollo. Conferencia llevada a cabo por el Área de Comunicación de la UASB, Quito.

Cordero Reiman, K., y Sáenz, I. (2007). Introducción. En K. Cordero Reiman e I. Sáenz (Comp.), Crítica feminista en la teoría e historia del arte (pp. 5-13). México: Universidad Iberoamericana y Universidad Nacional Autónoma de México.

Gebara, I. (2000) Sobre el ecofeminismo. Intuiciones Ecofeministas: Ensayo para repensar el conocimiento y la religión (pp. 17-33). Madrid: Editorial Trotta, S.A.

Rivera Cusicanqui, S. (2010). Ch'ixinakax utxiwa : una reflexión sobre prácticas y discursos descolonizadores. Buenos Aires: Tinta Limón. 